\title{
SURFACTANT-NUTRIENT MIX-ENHANCED BIOREMEDIATION OF SOIL/AQUIFERS
}

\author{
Uri Zoller \\ Haifa University, Israel
}

\begin{abstract}
Our research involves the development of economically feasible surfactant/surfactant-nutrient mix (SSNM) - enhanced bioremediation methodology for sustainable, in situ bioremediation of fuel-contaminated aquifers via in vitro column-based optimization of an effective SSNM and the study of its effect on the solubilization/mobilization and biodegradation of NAPL (fuel) in in vitro site/aquifer-simulated bioremediation. The essence of our findings: kerosene's maximum enhanced mobilization $-\mathrm{f}=3.6$, compared with that of deionized water, was achieved with an SSNM having the composition of linear alkylbenzene sulfonate: cocoamphodiacetate: surfactant-nutrient $X=0.15$ : 0.15 : $0.05 \mathrm{~g} / \mathrm{L}$, respectively; $60-64 \%$ of the initial amount of kerosene in the "packed" saturated soil matrix, has been eluted from it during $\sim 30$ days, compared with $\sim 87 \%$ of toluene during the same time period and $68 \%$ of kerosene biodegradation in "vessel" settings, in 21 days. In conclusion: The indigenous microorganisms present in the vaduse zones of fuel-contaminated sandy soil aquifers are capable of removing up to $\sim 81 \%$ of the initially contained kerosene in $\sim 42$ days. Optimized SSNMs enhance both, mobilization of the balky NAPLs and the desorbtion/solubilization/ dispersion of the entrapped NAPL which, in turn, facilitate their enhanced biodegradation.
\end{abstract}

\section{INTRODUCTION: THE PROBLEM, SCOPE AND BACKGROUND}

Contamination of soils, aquifers and groundwater by organic nonaqueous phase liquid (NAPL) pollutants; i.e., fossil fuels, chlorinated hydrocarbons and other organic chemicals, constitutes a major environmental issue of concern, worldwide $[6,10,8,7]$. The penetration of NAPLs into soil and groundwater is, in most cases, a result of accidents and improper codes of fuel handling and disposal. The migration of NAPLs in the soil occurs via various mechanisms such as advection, dispersion/dissolution, and diffusion resulting, ultimately, in accumulation of entrapped NAPLs as residual saturation in both the unsaturated and/or saturated zones of aquifers. The residual biodegradation-resistant hydrophobic fuel hydrocarbons entrapped in the soil porous matrix, possess a particular bioremediation challenge due to their becoming virtually immobile, nor desorbable or water dispersible and, consequently, they are not available as substrates, to the microorganisms-based biodegradation. As such, the NAPL pollutants constitute persistent organic pollutants (POPs) in the environment and their impact on groundwater resources is accordingly (Shih et al., 2004). Thus, petroleum-based fuel hydrocarbons (FHCs); e.g., kerosene, constitute a high contamination potential to soil and groundwater, due to their low viscosity and high persistence [6].

Due to their ability to bind to the soil particles, the entrapped residual NAPLs are not 
available to the soil microorganisms and may, therefore, remain intact and consequently biodegradation-resistant. From this perspective and that of sustainability remediation, in situ bioremediation appears to be the approach of choice $[10,4,11]$.

The selection of the appropriate surfactants mix, to be used, is crucial, since the surfactants (a) have to be biodegradable; (b) should, minimally, be adsorbed on the soil matrices [2]; (c) have to minimize potential reduction in hydraulic conductivity [3]; and (d) need to be optimized in order to obtain the lowest possible critical micelle concentration (CMC) in the mix $(1,5,9]$. Accordingly, The guiding objective of our research is the development of economically feasible, surfactant/surfactant-nutrient mix (SSNM)-enhanced bioremediation meth-odologies and technologies for sustainable, in situ, simultaneous bioremediation of the unsaturated and saturated zones of fuel-contaminated aquifers.

Our ideated technology requires, methodologically, (a) the development and optimization, via in vitro "vessel" (containers) and "flow" (columns) lab experiments and screening processes of the most effective mixture for the intended SSNM-enhanced bioremediation; and (b) the quantitative study of the combined effects of the optimized SSNM, in below CMC concentrations, on the solubilization/mobilization and biodegradation of NAPL (fuel) in the site/aquifer's simulated bioremediation, using toluene and kerosene as fuel representatives, and soil (as is) from the NAPL-contaminated site. The objective was, to examine the combined effect of our SSNM1 and/or SSNM2 mixtures [11] on the rate and extent of in situ biodegradation of entrapped LNAPLs in a sandy soil matrix of NAPL-contaminated aquifer.

\section{MATERIALS AND METHODS}

All experiments were carried out using sandy soil taken from Caesarea, an actual LNAPLcontaminated sandy coastal (of the Mediterranean Sea) site in Israel. It was used without any purification, drying or sieving. Toluene (ACS reagent, $99.5 \%+$ ), commercial kerosene and pre-optimized SSNM consisted of commercial linear alkylbenzene sulfonate (LABS) (Zohar, Detergent Factory, Israel) and commercially available surfactant-nutrient $X$ (Fluka, Switzerland), containing both $\mathrm{N}$ and $\mathrm{P}$ within its molecular structure were used. The remaining NAPL in the sandy soil-packed columns, at the end of the "flow" experiments, was soxhlet extracted, using n-hexane for kerosene and methylene chloride for toluene. The residual concentrations of NAPLs in the columns' soil and the eluents collected from the columns were determined by GLC. The mobilization's enhancement factor $f$ for the particular SSNM and NAPL used was determined as previously described [11]. "Vessel" experiments, under static conditions, were conducted during 21 days to determine the SSNM-unassisted biodegradation.

The full, detailed description of the column/flow and vessel/static lab experiments is provided else-where [12].

\section{SELECTED RESULTS AND DISCUSSION}

Based on previously accumulated experience, selected SSNMs have been prepared and their characteristics, relevant to this study, have been determined (Table 1). Based on these, particularly the mobility enhancement factor (MEF)- $f[11]$, mixtures 5 and 6 (Table 1; SSNM1 and SSNM2, respectively) have been selected for the simulating bioremediation studies. 
The mass balance of kerosene and toluene in the sandy soil columns treated with SSNM1\&2 $(\mathrm{f}=-2$ \& 3.6) during a total period of either 30 or 21 days, is presented in Table 2.

The maximum amount of toluene (6\%) was eluted (in using SSNM1) from columns filled with preheated $\left(110^{\circ} \mathrm{C}, 3\right.$ hours) sandy soil. This suggests that the efficiency of SSNMenhanced removal of the NAPL adsorbed on the soil's particles also depends on the soil's surface structure. The heat treatment alters this structure, resulting in reduced adsorption capacity of the soil's surface. Consequently, there is a decrease in the binding forces between the soil's surface and the adsorbed pollutant. In addition, the presence of the SSNM1 lowers the interfacial tension between the entrapped residual toluene and the aqueous phase. These combined two factors lead to the resulting increase in both the mobility and amount of toluene eluted from preheated sandy soil $-6 \%$ compared to just $2 \%$ of toluene eluted from the unheated matrix.

During the 30 days of these flow/column experiments (non-preheated sand), the amount of toluene, degraded within the sandy soil treated with deionized water and with SSNM1, was about the same $-86 \%$ of the initially introduced amount.

Table 1. Characteristic parameters of optimized, aqueous surfactants-surfactant-nutrient mixtures used for the enhancement of NAPLs (kerosene) mobility in sandy soil matrices.

\begin{tabular}{|c|c|c|c|c|}
\hline Aqueous system/surfactants & $\begin{array}{l}\text { Hydraulic } \\
\text { Conductivity }\end{array}$ & $\begin{array}{c}\text { Mobility } \\
\text { Enhancement } \\
\text { Factor }\end{array}$ & $\begin{array}{c}\text { Kerosene } \\
\text { Solubility in } \\
\text { Aqueous } \\
\text { Surfactants-Mix } \\
\text { Solutions } \\
\mathrm{S}(\mathrm{mg} / \mathrm{l})\end{array}$ & $\begin{array}{c}\text { Partition } \\
\text { Coefficient of } \\
\text { Kerosene } \\
\text { between } \\
\text { Water and } \\
\text { Sand Phases } \\
\mathrm{K}_{\text {WS }} \times 10^{2}\end{array}$ \\
\hline 1. Water & 3.3 & 1.9 & 0 & 0 \\
\hline 2. Surfactant $A^{(a)}(0.15 g / L)+X^{(b)}(0.05 g / L)$ & 6.4 & 3.6 & 4.9 & 10 \\
\hline 3. Surfactant $D^{(c)}(0.15 \mathrm{~g} / \mathrm{L})+X(0.05 \mathrm{~g} / \mathrm{L})$ & 5.9 & 3.6 & 9.2 & 23.6 \\
\hline 4. Surfactant $D(0.20 \mathrm{~g} / \mathrm{L})+X(0.05 \mathrm{~g} / \mathrm{L})$ & 5.6 & 3.2 & 6.7 & 17.1 \\
\hline $\begin{array}{l}5^{(\mathrm{d})} \text {. Surfactant A }(0.15 \mathrm{~g} / \mathrm{L})+\text { Surfactant D } \\
(0.10 \mathrm{~g} / \mathrm{L})+\mathrm{X}(0.05 \mathrm{~g} / \mathrm{L})[\text { SSNM } 1]\end{array}$ & 4.1 & 3.0 & emulsion & emulsion \\
\hline $\begin{array}{l}6^{(\mathrm{e})} \text {. Surfactant A }(0.15 \mathrm{~g} / \mathrm{L})+\text { Surfactant D } \\
(0.15 \mathrm{~g} / \mathrm{L})+\mathrm{X}(0.05 \mathrm{~g} / \mathrm{L})[\mathrm{SSNM} 2]\end{array}$ & 6.4 & 3.6 & 11.7 & emulsion \\
\hline
\end{tabular}

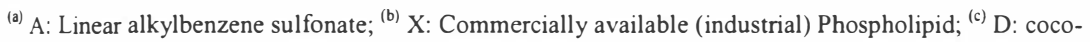
amphodiacetate;

(d) SSNM1; (e) SSNM2 
Table 2. Mass balance of NAPLs (kerosene and Toluene) in a lab-controlled bioremediation of NAPL-contaminated sandy soil.

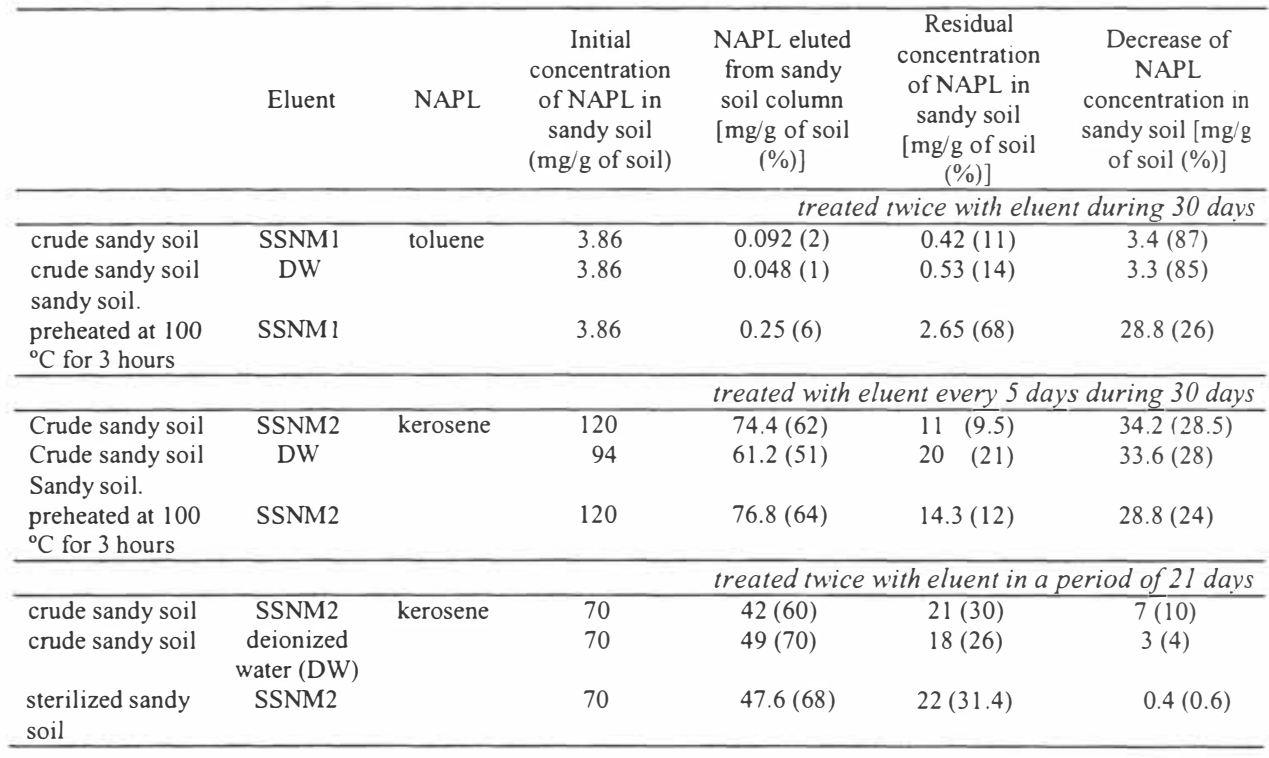

The highest value of $\mathrm{f}$ for kerosene mobilization in sandy soil was found to be 3.6 for SSNM2 (Table 1). Therefore, the latter was used in the kerosene-contaminated sandy soil remediation study. The most significant result which was observed in all flow experiments with sandy columns, using either SSNM2 or deionized water, was the elution of significant amounts of kerosene by both eluents.

Thus, $43-50 \%$ of the kerosene in the soil matrix was eluted from sandy soil columns in the first day of the experiment on passing the eluent through the columns, 5 hours after the introduction of the kerosene. Significantly, less amount of kerosene (2-19\%) was eluted from these columns during the remaining days. The average total amount of kerosene eluted from the sandy matrices during the experimental period was $60-70 \%$ of the initial amount. On using aqueous solutions of SSNM2, the removal of kerosene was found to be within the range of $60-68 \%$, independent on the initial amount of kerosene in the soil matrix. Significantly, the amount of kerosene eluted from sandy soil columns on using deionized water varied, depending on the initial concentration of the kerosene in the sandy matrix.

In sandy soil columns, treated twice with eluent during a total period of 21 days, just $4-10 \%$ of the kerosene introduced was biodegraded. The amount of biodegraded kerosene in sandy columns, treated with the eluent each 5 days during 30 days, amounted to $28-28,5 \%$. These results indicate, that the rate of kerosene's biodegradation in sandy soil matrices is directly dependent on the degree of saturation of the soil with the eluent.

In all of the experiments (Table 2) the amount of the biodegraded kerosene was almost the same both in sandy soil columns treated with SSNM2 and those treated with deionized water; 
i.e., in columns treated twice with eluent during 21 days $-10 \%$ and $4 \%$; in columns treated with eluent every 5 days during 30 days - 28,5\% and 28\%; and in vessels (hermetically sealed) containing sandy soil and saturated with eluent during 21 days $-68 \%$ and $62 \%$. Thus, under the experimental conditions employed the use of SSNM2 didn't affect the rate of kerosene's biodegradation in sandy soil, compared with the use of deionized water. A plausible explanation may be, that the relative short time residence of the kerosene in the soil matrix (ca. $80 \%$ of the initial load is eluted in 2 days) is not suffinient for the former to be, actually "entrapped" in the latter. Nevertheless, biodegradation of the NAPL kerosene did occur in both cases.

\section{CONCLUSIONS}

1. The microorganisms in the sandy soil, taken from the field site studied, are capable of biodegrading both toluene and kerosene, removing up to $86 \%$ and $68 \%$, respectively, of their initial concentrations during 30 and 21 days, respectively. The rate of kerosene's biodegradation in sandy matrix depends on the degree of saturation of the latter with the eluent (SSNM2 or water).

2. Microorganisms present in the soil in an inactive state form of spores, are able to degrade kerosene and toluene (24-26\% of the initial concentration during 30 days), contingent on appropriate conditions for their vital activity.

3. Under the experimental conditions employed, SSNM did not affect the rate of LNAPLs (kerosene and toluene) biodegradation in sandy soil, compared with that in deionized water. Thus, the major effect of the SSNM addition is the enhanced mobilization of the balky NAPL and the enhanced desorbtion and solubilization/dispersion rates of the entrapped NAPL in the soil matrix.

\section{REFERENCES}

[1] Bettahar, M., Shäfer, G., Baviere, M., 1999. An optimized surfactant formulation for the remediation of diesel oil polluted sandy aquifers. Environ. Sci. Technol. 33(3), 12691273.

[2] Cheng, H., Sabatini, D.A., 2002. Simultaneous uptake of nonionic surfactants and micellar-solubilized contaminants using anion-exchange resins. Wat. Res. 36(8), 20622076.

[3] Jain, V., Demond, H., 2002. Conductivity reduction due to emulsification during surfactant enhanced-aquifer remediation. 1. Emulsion transport. Environ Sci. Technol. 36(24), 5426-5433.

[4] Lesage, S., Zoller, U., 2001. What is sustainable remediation? J. Environ. Sci. Health. A $36(8)$, vii-xiii.

[5] Lomax, E., 2001. Resolving property conflicts in surfactant formulations. Chim. Oggi/Chem. Today, June, 47-50.

[6] Rubin, H, Braxein, A, Daniels, H, Rouve, G., 1994. Migration of oil and petroleum pollutants in soils and groundwater. In: Groundwater Contamination and Control, U. Zoller (ed.), Marcel Dekker, Inc, New York, pp. 355-375.

[7] Shih, T., Rong, Y., Harmon, T., Suffet, M., 2004. Evaluation of the impact of fuel hydrocarbons and oxygenates on groundwater resources. Environ. Sci. Technol. 38(1), $42-48$.

[8] Stroo, H.F., Unger, M., Ward, C.H., Kavanaugh, M.C., Vogel, C., Leeson, A., Marqusee, J.A., Smith, B.P., 2003. Remediating chlorinated solvent source zones. 
Environ. Sci. Technol. 37(11), 224A-230A.

[9] Zheng, Z., Obbard, J.P., 2002. Evaluation of an elevated non-ionic surfactant critical micelle concentration in a soil/aqueous system. Wat. Res. 36(1), 2667-2672.

[10] Zoller, U., 1998. In-situ bioremediation of residual entrapped NAPL in aquifers by a biodegradable nutrient-surfactant Mix. In: Soil and aquifer pollution, H. Rubin, N. Markis and J. Carberry (eds.), Springer-Verlag, Berlin, Heidelberg, pp. 322-334.

[11] Zoller, U., Rubin, H., 2001. Feasibility of in situ NAPL-contaminated aquifer bioremediation by biodegradable nutrient-surfactant mix. J. Env. Sci. Health, Part A, A 36(8), 1451-1471.

[12] Zoller, U., Reznik, A., 2005. In-situ surfactant/surfactant/nutrient mix-enhanced bioremediation of NAPL (fuel)-contaminated sandy soil/aquifers. Environ. Sci. Poll. Res. (submitted for Publication). 